\section{Validity of the Membership Examination} DEAR SIRS

I was interested to read correspondence in the Bulletin (October 1985, 9, 204) on the validity of the Membership Examination. The point is made by one of your readers that because someone has won the Gaskell Medal and yet failed the Membership Examination, this implies a defect in the College Examination.

While it might well do that it could equally suggest a defect in the construction and application of the Gaskell Medal. One perhaps should suggest that those who set and test within these examinations should also look to their systems and make appropriate amendments.

Perhaps more to the point, the two examinations-the Gaskell Medal on the one hand and the College Examination on the other-test rather different areas of expertise. One wonders whether one would prefer to be treated by a psychiatrist who had won the Gaskell Medal or by a psychiatrist who had passed the Membership Exam.

M. T. HASLAM

\section{Clifton Hospital}

York

DeAR SIRS

Dr Appleby (Bulletin, October 1985, 9, 204) requested the newly elected Fourth Collegiate Trainees' Committee to examine the validity of the MRCPsych Examination. We would agree that it is difficult to design an examination that is valid for the art as well as the science of psychiatry. The previous CTC presented the trainees' views on this and many other subjects to the Working Party reviewing the MRCPsych.

Although cost (borne directly by the examination candidate) and unreliability of assessment has prevented the revised examination from incorporating some of the new technologies (such as videotaping to assess interviewing skills), the CTC believes that the new examination will be an advance on the old. This is particularly true of the new Preliminary Test now that this will become a more comprehensive screening test.

A particular advance is the monitoring of the performance of the exam itself which hopefully will continue to suggest improvements in reliability and validity. No examination exists without fault and the CTC is particularly keen to learn the views of trainees regarding constructive criticisms of, and suggestions about, the new examination, once the plans for change are published, as well after implementation.

Peter White Chairman

Collegiate Trainees' Committee

\section{Consultant Based Services}

DeAr Sirs

The President (Bulletin, June 1985, 9, 118) intends the College to monitor a proposed Consultant Based Scheme in Hartlepool, staffed predominantly by academics. The concern of the Collegiate Trainees' Committee has been described (Bulletin, February 1985, 9, 34) and we have formed a Working Party to investigate the implications of Consultant Based Services.

We would like to hear from consultants working within the NHS who are already providing a Consultant Based Service, explaining the organisation of their work, its advantages, and problems they have encountered.

R. G. Poole Convenor

Working Party on Consultant Based Services

Collegiate Trainees' Committee

\section{Pretentious? Moi?}

Dear Sirs

Entre nous, one of my bêtes noires, inter alia, are those irritating authors who habitually quote vast chunks of foreign languages sans translation. Despite the fact that knowledge of Latin has long ceased to be a requirement for qualification in medicine, doctors seem particularly prone to obfuscation. The cloaking of ignorance and superstition by the spurious erudition of classical languages has a long tradition. Most examples are harmless enough, and one risks being thought of as pompous and po-faced if one protests too vehemently that communication should always fulfil its purpose: the unambiguous transfer of information.

For those like myself who can order a beer and sandwich in two or three European languages, but only have a fluency in the language of their birth, I have compiled some frequently used psychiatric terms, with their translation. We are all familiar with the Sehrkulturmann, the type of psychiatrist who feels obliged to include a German reference whenever possible: 'Gottimhimmelpekker'penis envy; 'Hanselängstgretelbekommen'-castration anxiety; 'Ängstmuttersprechenaufwiedersehenpet'- separation anxiety. There is also the Latin: 'Gaudeamus igitur'-literally 'let us rejoice' (buying the drinks when your psychopathic patient doesn't show up); 'Reductio ad absurdam'-falling about at your trainee's hypothesis; 'Et tu Brute!'-overdoing the after-shave to enhance transference. And finally the French; 'Faux pas'-step-father; 'A la carte'-climbing on the object relations bandwagon; 'Dieu et mon droit'-God knows I'm right.

ROBERT WILKINS

10 Avonmore Avenue

Guildford, Surrey

\title{
Review of the MRCPsych
}

The Report of the Working Party for Review of the MRCPsych is available to all trainees, Members and Fellows of the College. If you wish to obtain a copy, please send an s.a.e. (C4 size) to the Examinations Officer at the College. 